\title{
İnternet Üzerinden Tezlere Tam Metin Erişim: Bir Model Önerisi
}

\author{
Full-text Access to Theses via Internet: A Model Proposal
}

\section{Mehmet Boz ${ }^{*}$}

\section{Öz}

Internet ve bilgi teknolojilerindeki hızlı gelişme sonucunda yeni bir boyut kazanan bilgi hizmetleri, büyük bir değişime uğramaktadır. Elektronik ortamda iletişimin ve paylaşımın artması nedeniyle bilgiye en hızlı şekilde ulaşmak, bilgi hizmetlerinin temel amacını olmuşturmaktadır. Bu amaçtan hareketle, bilgi kaynakları içinde önemli bir yer tutan tezler de yeni bir boyut kazanmış, tam metinlerine elektronik ortamda erişilerek çok daha etkin bir şekilde kullanılmaya başlanmıştır.

Ülkemizde de tezlerin internet aracılığıyla daha etkin kullanılabilmesi için alt yapı, depolama ve arşivleme, erişim yönetimi ve indeksleme gibi ögelerin incelenmesi gerekmektedir. Bu makalede, öğrencilerin tezlerini elektronik ortamda yazmalarından kütüphaneye göndermelerine, tezlerin indekslenmesi ve arşivlenmesinden tam metin olarak kullanıcıların erişimine açılmasına kadar yapılması gereken işlemler üç aşamada incelenmektedir.

Anahtar sözcükler: Elektronik tezler, E-tez-Tam metin erişim.

\begin{abstract}
Information services gained a new dimension as a result of the rapid developments in information technologies and Internet. As a consequence of the developments in communication and cooperation facilities in the electronic environment, getting access to information quickly has become the main objective of information services. Hence, theses that fulfil an important function in the provision of information services in general have gained a new dimension as well: theses that are accessible full-text through Internet have been used in a much more effective way.

In order for theses to be made accessible more effectively via Internet in Turkey, the components such as infrastructure, storage, archiving, access management and indexing should be studied. In this article, in three steps, the overall process from preparation of the theses in electronic environments to the submission of them to library, from indexing and archiving of theses at the library to making their full-texts available to users via Internet.
\end{abstract}

Keywords: Electronic theses and dissertations, E-Theses-Full text access.

\footnotetext{
“Uzman Kütüphaneci. ULAKBIM (mehmet@ulakbim.gov.tr).
} 


\section{Giriş}

Araştırmacıların bilgi intiyacının karşılanmasında kullanılan çok çeşitli bilgi kaynakları bulunmaktadır. Bu bilgi kaynaklarından biri olan tezler, ülkemiz açısından mevcut bir takım sorunlar nedeniyle araştırmacıların hizmetine yeterince sunulamamaktadır. Temel olarak bibliyografik denetimin yetersizliği, üniversite veya ticari yayıncılar tarafından basılamaması, hizmete sunulan tezlerin zamanında duyurulamaması ve telif hakları konusundaki problemlerin tam olarak çözülememesi gibi nedenler bu sorunların başında gelmektedir. Ayrıca kütüphanelerin diğer bilgi hizmetlerinde karşılaştıkları problemlerden, personel, alt yapı ve kaynak eksikliği gibi sorunların tezler için de geçerli olması, etkin kullanımını olumsuz yönde etkileyen faktörler arasındadır.

Bilgi teknolojilerinde yaşanan gelişmeler ile birlikte tez hizmetleri de yeniden şekillenmeye başlamıştır. Tezlerin teslim aşamasından başlayarak depolama, arşivleme, indeksleme ve hizmete sunulmasında yeniden yapılanmalar sayesinde, yurt dışında olduğu gibi tezlerin tam metinlerine erişim için ülkemizde de çeşitli modeller oluşturulabilir. $\mathrm{Bu}$ makale, tezlerin tam metin olarak hizmete sunulabilmesinde izlenecek yollar konusunda bilgi vermeyi amaçlamaktadır. Bu bilgilerden hareketle elektronik tezlerin (e-tez) ögeleri ve hizmete sunulmasında izlenecek basamaklar sonucunda çeşitli model önerileri geliştirilebilir.

\section{Elektronik Tez}

Tez ve elektronik tez olarak ifade edilen çalışmalar için bazı tanımlar getirilmiştir. Tez, kısaca "akademik bir derece veya diploma kazanmak için hazırlanan bir bilimsel inceleme veya rapor" olarak tanımlanmaktadır (Prytherch, 1995, s.207; aktaran: Bahşişoğlu, 2000, s.42). Elektronik ortamda hazırlanan (veya sonradan elektronik ortama aktarılan), arşivlenen ve erişime açılan tezlere ise "elektronik tez (e-tez)" adı verilmektedir (Case, 1998; Waterloo University, 1997).

İnternet ve bilgi teknolojileri sayesinde artan iletişim ve paylaşım sonucunda, zaman ve mekân sınırlaması olmaksızın tezlerin tam metin erişimi ile daha çok kullanıcıya hizmet verilebilmektedir. Bu teknolojik gelişmelere paralel olarak kütüphaneler, bilgi hizmetlerindeki rollerini yeniden düşünüp, tarihsel bakışlarının ve alışılmış görevlerinin yanı sıra bilgi iletişimi için tezleri de dikkate almaya başlamışlardır (McMillan, Fox ve Eaton, 1999). 
Gelişen bilgi ve iletişim teknolojileri sayesinde tezlerin elektronik ortamda yazılması ve teslim edilmesi, basılı tezlere oranla daha az personel ile daha kısa zamanda erişime açılması, tüm metnin taranabilir ve indekslenebilir olması, kataloglama işlemlerini basitleştirmesi, depolama ve erişimde birçok yeni olanağa kavuşması sayesinde dünyada e-tezler için önemli projeler geliştirilmiştir. Özellikle ABD, İngiltere, Kanada ve Avustralya gibi ülkelerde 1996 yılından itibaren yoğun çalışmalar göze çarpmaktadır. Türkiye'de de tezler konusunda mevcut durum, göz önüne alınarak e-tez hizmetleri için çeşitli erişim modelleri geliştirilmelidir.

Tezlerin elektronik ortamda tam metin hizmete sunulabilmesi ile tez yazarlarının, kütüphanelerin ve/veya bu işi üstlenen kurumların hem e-tez işlemlerinin yapılması ve hizmete sunulmasında, hem de kullanıcıların yararlanmasında önemli avantajlar elde edecekleri bir gerçektir.

\section{Elektronik Tez Ögeleri}

Elektronik tezlerin internet üzerinden tam metin erişime açılabilmesi için, öğrenciler tarafından tezin yazımından başlayarak elektronik ortamda teslim edilmesi, telif hakları, depolama ve arşivleme, indeksleme, erişim yönetimi, mevzuat ve yönetmelikler ile bunlara ait alt yapı intiyaçları giderilmelidir.

Ülkemizde tezlerin hizmete sunulmasında, gerek önceden yapılmış gerekse bundan sonra yapılacak olanların elektronik ortamda teslim edilmesinde, depolanması ve arşivlenmesinde ortaya çıkan sorunlar irdelenmelidir. Ayrıca tezin erişiminde kullanılacak doğru indeks terimlerinin verilmesi ve bibliyografik denetimde belirli standartlara uyulması da tüm e-tez erişim modelleri için büyük önem taşımaktadır. Bu noktada e-tezlerin içeriğine tam metin erişimde belirlenecek kıstaslar, sınırlamalar, kullanılacak format veya kullanıcı arayüzü gibi erişim ve erişim yönetimini ilgilendiren konuların açıklığa kavuşturulması gereklidir. E-tezler hakkında oluşturulacak politikalar, kurulacak kontrol mekanizması ile hangi kullanıcı gruplarının elektronik kaynağa nasıl ulaşabileceğini, erişime nasıl izin verileceğini veya sınırlanacağını ve erişim yönteminin şeklini belirlemede etkili olacaktır (Arms, 1998).

Türk üniversitelerinde kabul edilen tezlerin elektronik ortamda hizmete sunulması için üzerinde durulması gereken bir diğer nokta teknik alt yapı konusudur. Teknik alt yapı denildiğinde ise, tez merkezinin/merkezlerin kurulması ve işletilmesi için, doğrudan veya dolaylı olarak görevli kişi ve kurumların intiyaç duydukları, yüksek 
bant genişliğine sahip bilgisayar ağları, gereken tüm bilgisayar donanım ve yazılımları, sunucular ve yedekleme üniteleri gibi diğer teknik unsurlar akla gelmektedir. Örneğin, tez ile ilgili belgelerin ve resimlerin elektronik ortama aktarılması için tarayıcı, lazer ve renkli yazıcı, sayısal kamera, CD yazıcısı gibi donanımlar ile depolama için format dönüştürücü, kelime işlemci ve resim editörleri gibi yazılımlar sağlanmalıdır (Thomas, 1998). Ayrıca tez merkezi için, her gün çok sayıda bağlantı alabileceği ve programların kolayca çalışabileceği yeterli hafızaya sahip sunucuların, depolama için disk alanı ve sürekli artan e-tezleri arşivlemek için yeni diskler, yedekleme için teyp sürücü ve CD-ROM kaydedici donanımlar bunlardan bazılarıdır. Ayrıca e-tezlerin taranabilmesinde tasarlanacak kullanıcı arayüzü de sayısal e-tez kütüphaneleri için oluşturulması gerekli alt yapılardan birisidir (Thomas, 1998).

Elektronik tezlerin, basılı tezlerden farklı olması nedeniyle karşılaşılan telif hakları konusu, tezlerin tam metin hizmete açılması için çözümlenmesi gereken önemli sorunlardan birisi, belki de en önemlisidir. Basılı eserlerde eser sahibinin hakkının korunması, yayıncı ile eserin çoğaltılmasını sağlayan fotokopilerin kontrolü ile daha kolaydır. Oysaki, elektronik ortama aktarılmış bilginin kopya edilebilmesi ve mekândan bağımsız olarak kolayca dağıtılabilmesi telif hakkının korunmasını zorlaştırmakta ve bir eserin çok sayıda kopyasının çıkarılarak dağıtılabilmesi nedeniyle telif haklarının korunması büyük sorun olmaktadır (Rusbridge, 1995). Bu durum tezler için de aynıdır. Tezin tam metin olarak elektronik ortamda ulusal ve uluslararası bilim toplumunun hizmetine açılması, yazarların bunun için gerekli izinleri vermesine bağlı olarak belirlenecek erişim yönetimi ile sağlanmalıdır.

Telif hakkı sahiplerinin vereceği izinlere bağlı olarak tezlere kimin, nasıl ve hangi sınırlar içinde erişebileceği saptanmalıdır. Geleneksel tez hizmetlerindeki en önemli sorunlardan birisi olan teze erişim izinleri, elektronik ortamda izlenecek yöntemler ile düzenlenmelidir. Elektronik formattaki bilgi ve kaynaklara erişimde olduğu gibi, etezlerin erişiminde de kimin, nasıl ve hangi sınırlar içinde tezlere ulaşabileceği belirli yönetimsel kurallar içinde olmalıdır. Sınırlı veya sınırsız erişime sahip kullanıcıların nasıl saptanacağını, hangi kriterlere bağlı olarak nasıl erişim sağlayacakları da belirlenmelidir. Bunun için de sistem mimarisi, erişim modelleri ve sorgulama stratejileri ortaya konmalıdır (Gudivada, Raghavan, Grosky ve Kasonogottu, 1997). Elektronik bilgiye erişimde kullanılan birkaç erişim yöntemi bulunmaktadır. En yaygın 
olarak kullanılanlar "kullanıcı adı-şifre", "IP (Internet Protokolü) numarası" ve "proxyvekil" modelleridir (Lynch, 1996).

Erişim yönetimi ile tezin içeriğine bağlı olarak belirlenecek erişim kriterlerinin oluşturulmasının ardından, e-tezlerin indeksleme işlemi gelmektedir. Elektronik ortamdaki bilgilerin indekslenmesi hem elle hem de otomatik olarak yapılabilmektedir. Ancak elle yapılan indeksleme zaman, insan gücü ve bunların sonucu olarak ortaya çıkan maliyet nedeniyle pratik değildir. Otomatik indekslemede ise verilen anahtar sözcükler için sıkı bir kelime kontrolü mümkün olmayabilir (Gudivada ve diğerleri, 1997). İndeksleme işlemlerinde elektronik bilgilere erişim için uluslararası bir standart olma yolundaki (başlık, yazar veya yaratıcı, konu ve anahtar sözcük gibi 15 alandan oluşan) Dublin Core metadata ögeleri, kullanılabilir (Dublin Core, 2002). Ancak tezlerde, danışman ve jüri gibi özel alanların bulunmasından dolayı Dublin Core bu konuda eksik kalmaktadır. Bu nedenle Dağıtık Sayısal Tez Kütüphanesi (Networked Digital Library of Theses and Dissertations-NDLTD), e-tezler konusunda metadata alanlarında bazı değişiklikler yaparak 14 girişten oluşan bir standart geliştirmiştir (NDLTD, 2001).

Elektronik ortamdaki bilgilerin arşivlenmesi, bu bilgilerin korunması, erişimi ve devamlıı̆ı için gereklidir. Elektronik bilginin depolanması ve buna bağlı olarak korunması, bu bilgilerin gelecek kuşaklara aktarılmasını sağlar. Sayısal formatta depolanan kayıtlara gelecekteki teknolojiler ile sürekli olarak erişim güvence altına alınmalı, bu amçla eski teknoloji format ve standartlar yerine yeni format ve standartlar konulmalıdır (Garrett, 1995). Mevcut bilgiler, devamlıı̆ın sağlanabilmesi için yeni teknolojiler kullanılarak kopyalanmalıdır (migration). Kopyalama, eski teknoloji ile üretilmiş elektronik bilginin zaman zaman daha yeni teknoloji ile üretilmiş ortamlara aktarılması anlamına gelir (Tonta, 1999). Depolama ortamlarındaki temel sorun yazılım ve donanım teknolojilerinin hızla eskimesidir. E-tezler için de durum farklı değildir. Bu konuda ABD'deki Virginia Teknik Üniversitesi (1998), tezlerin uygun olan tüm formatlarda saklanmasına karar vermiştir. Buna göre üniversite arşivi tezlerin basılı kopyalarını ciltleyip saklarken, üniversite kütüphanesi de kendi standartları, politikaları ve prosedürleri ile e-tezleri elektronik ortamda arşivlemeye devam etmektedir.

Yukarıda üzerinde durulan bu ögelerin dışında, ülkemiz açısından önemli bir nokta da tezler ile ilgili mevzuat ve yönetmeliklerin yetersizliğidir ve üzerinde önemle 
durulmalıdır. E-tezleri hizmete sunmak için düşünülmesi gereken bir unsur da, sistemin düzenini, devamlıı̆ını ve denetimini sağlayacak ilgili mevzuat ve yönetmeliklerin oluşturulmasıdır. Mevcut sistem içerisinde uygulamadaki mevzuat ve yönetmelikler, yeni durumu karşılayacak şekilde yeniden düzenlenmeli ve değiştirilmelidir. Öğrencilerin tezlerini hangi koşul ve kıstaslara bağlı olarak hazırlayacaklarına, nasıl teslim edeceklerine ve telif hakkı sorunlarının çözümüne yönelik değişikliklere veya yeni yönetmeliklere intiyaç vardır. Örneğin; öğrencinin tezi hazırlamadan önce bilmesi gereken kuralları belirleyen "Tez Hazırlama Kılavuzu”nun, “Elektronik Teslim Politikası”nın, yüksek lisans ve doktora öğrencilerinin sözlü savunma kurallarının belirlenmesi gibi (North Caroline State University, 2002).

\section{Tam Metin Erişim Modellerinde Elektronik Tez İşlem Aşamaları}

Türkiye'de internet üzerinden tam metin hizmet verebilecek e-tez merkezi/merkezlerinin kurulması ve hizmet vermesi üç aşamada incelenebilir. Birinci aşama, e-tezin öğrenci tarafından yazııması, teze çoklu ortam ürünlerinin eklenmesi ve belirlenecek formatta tez merkezine teslim edilmesidir. Bu işlemler yapılırken, öğrencilerin uyması gereken kuralları ve yönetmelikleri düzenleyen enstitülere ait görev ve sorumluluklar da bu aşamada ortaya konulmaktadır. İkinci aşama, e-tezin merkeze teslim edilmesinden başlayarak hizmete sunulmasına kadar yapılacak teknik işlemleri kapsamaktadır. Tezlerin hizmete sunulmasını içeren üçüncü aşamada ise, uygulanacak erişim yönetimi, erişim formatları ve kullanıcı arayüzü gibi noktalar üzerinde durulmaktadır.

\section{Birinci Aşama: Tez Yazımı ve Elektronik Teslim Işslemleri}

Tezlere tam metin erişim modellerinin birinci aşaması, yüksek lisans, doktora, tıpta uzmanlık ve sanatta yeterlilik çalışmalarını öğrenciler tarafından üretilmesi ve teslim edilmesidir. Bu aşamada ilgili merkez/merkezlerin karar vermiş olduğu ve enstitüler tarafından tez yazım ve basım yönetmeliklerinde belirtilen formatlarda, tezin yazılması ve gerekli çoklu ortam ürünlerinin eklenmesi işlemleri yapılmaktadır.

Elektronik tez için tercih edilen dosya ve çoklu ortam ürün formatlarından, günümüzde en yaygın olanları, Windows işletim sistemini kullanan bilgisayarlarda tablo ve metin için Microsoft Office yazılımları (Word, Excel), Star Office ile Linux/Unix işletim sistemi altında çalışan bilgisayarlar için ise Postscript, TeX ve Latex gibi yazılımlardır. Resim için TIFF, JPEG, GIF, bitmap ile video için AVI, MPEG 
gibi formatlar yaygındır. Ancak bu aşamada üzerinde durulması gereken en önemli nokta, kullanılacak olan bu formatların sürekli güncellenmesi, ihtiyacı karşılayamayacak olanların mevzuat ve yönetmeliklerden çıkarılmasıdır.

Tez araştırmasının ardından metnin kelime işlemcide yazıımasında öğrenciler genelde kişisel bilgisayarlarını, okulda bulunan bilgisayar lâboratuvarlarını kullanmakta veya bu işi yapan özel şirketleri tercih etmektedirler. Gerek kişisel bilgisayarlarda, gerekse bilgisayar lâboratuvarlarında tez metninin yazımı ve renkli resim, çoklu ortam ürünleri, tablo ve grafiklerin hazırlanabilmesi ve eklenebilmesi için uygun yazılım ve donanım ürünleri sağlanmalıdır. Örneğin, gereksinim duyulan belgelerin, resimlerin elektronik ortama aktarı Iması için tarayıcı, lazer ve renkli yazıcı, sayısal kamera, video, CD yazıcısı gibi donanımlar ile resim ve grafik editör programlarının ortak kullanımdaki lâboratuvarlarda bulunması tez yazımını öğrenciler açısından oldukça kolaylaştıracak ögelerdir.

Elektronik tezin maliyet oluşturacak asıl kısmı olan ve yukarıda belirtilen alt yapının tüzel kişi ve kurumlarca karşılanması, öğrencilerin tezlerini elektronik ortamda hazırlamaya ve sunmaya kolaylıkla uymalarını sağlayacaktır. Ülkemizdeki öğrencilerin mali durumlarının yüksek bilgi teknolojisi programlarını edinmeye genellikle yetmediği göz önüne alınmalıdır. Bilgi teknolojilerinin gelişmesi ile fiyatlarda düşme olsa da, öğrenciler için e-tez hazırlama maliyeti, sistemin yürümesinde sorunlar yaratabilir. Bu nedenle üniversitelerin bu maliyetleri üstlenmesi öğrencilere büyük kolaylıklar getirecektir.

Öte yandan, ülkemizdeki öğrenci profiline genel olarak bakıldığında bilgisayar okuryazarlığı açısından da yetersiz oldukları bilinmektedir. Bu nedenle, öğrencilerin tez yazımı sırasında kullanacakları yazııım ve donanım ürünlerinde karşılaşacakları problemlerin çözümüne yardımcı olabilecek teknik personel intiyacı öne çıkmaktadır. Bu durumda bölümlerde teknik danışmanlık hizmeti veya bilgisayar okuryazarlığı dersleri verilmelidir. Bölüm kadrosundaki teknik danışman, bilgisayar ve bilgi teknolojileri konusunda yeterli bilgiye sahip olmalıdır.

Tezin yazımı ve çoklu ortam ürünlerinin eklenmesinin ardından, tez jürisi tarafından kabul edilen çalışma, "Jüri Onay Formu" ile birlikte belli sayıda basılı kopya olarak enstitüye verilmelidir. Ancak bu işlemden önce tezin basılı ve elektronik kopyasının ve tarayıcıdan geçirilerek elektronik ortama aktarılan Jüri Onay Formunun merkeze veya basılı kopya gibi enstitüye teslim edilmesi ve buna dair belge alınması 
gereklidir. Tezin yazarı tarafından enstitüye verilmesinde izlenecek yol, merkez tarafından düzenlenen "Elektronik Tez Teslim Prosedürleri” ile belirlenmelidir. Ayrıca e-tez kopyası, basılı kopya ile aynı olan iki farklı formatta olmalıdır. Birincisi tezin kelime işlemcide yazılmış doc veya TeX, LateX formatları, merkez tarafından otomatik indekslemede ve basılı kopya siparişlerini karşılamada kullanılmak üzere talep edilebilir. İkincisi ise PDF (portable document format) veya Postscript formatında elektronik kopyası olmalıdır. Böylece tezin bilgisayar ve teknoloji farklılıklarına karşı basılı kopya ile aynı sayfa ve düzende olması sağlanabilir.

Elektronik tezlerin tesliminde kullanılacak olan Elektronik Tez Teslim Formu, merkezin veya enstitünün web sayfasında herkesin kullanımına açık olmalıdır. Ayrıca formun doldurulmasında tez yazarlarının karşılaştıkları sorunları cevaplayabilecek yeterliliğe sahip yardım sayfalarının bulunması, e-tezin teslimindeki sorunların en aza indirilmesinde yardımcı olacaktır. Her üniversite e-tezin teslim yönteminde kendine göre bir akış tespit edebilir. Örneğin, istenilen formatlarda e-tezin enstitüye disket ile teslim edilmesi sağlanabilir.

Yazarların tezlerini elektronik olarak teslim etmeleri esnasında yapılacak bir işlem de, merkezin indeksleme işlemlerinde yardımcı olacak anahtar sözcüklerin belirlenmesidir. "Elektronik Tez Teslim Formunda" veya teslim anında ayrı bir dosya şeklinde istenecek anahtar sözcüklerin, araştırmasına hakim olan yazar tarafından verilmesi, indeksleme yapan kütüphanecilere kolaylık sağlayacaktır.

Tezlerin elektronik ortamda tam metin olarak hizmete açılabilmesi için telif hakkı sahiplerinden gerekli izinler alınmalıdır. Bu izinler yazarlarla yapılacak "telif hakkı anlaşması" ile elde edilebilir. Örneğin, tezin tamamının hiçbir sınırlama getirilmeden veya sadece belirli bölümlerinin erişime açılması ya da yalnızca üniversite içi hizmete sunulması gibi seçeneklerle bu anlaşma yapılabilir. Böylece e-tezler için gereken erişim yönetim sistemi sağlıklı bir şekilde oluşturulabilir. Eğer tezin merkez yerine enstitüye teslim edilmesi planlanırsa, işlem basamakları, enstitülerin teknik alt yapı ve iletişim olanaklarının da geliştirilmesine yönelik olarak gözden geçirilmelidir. Bu durumun, hizmetlerin hızlı ve etkin bir şekilde yürümesinde önemli bir rol oynayacağı üzerinde düşünülmesi gereken bir noktadır.

Elektronik tezin merkeze iletilmesi ile yukarıda belirtilen süreci tamamlayarak "Elektronik Tez Teslim Belgesi”ni alan öğrencinin yapacağı son işlem, bu belge ile birlikte tezin elektronik ve tıpkı basılı kopyalarını enstitüye vermektir. Bu noktada 
enstitülere düşen en önemli görev, tezin ilgili merkeze teslim edilmesini denetlemektir.

Birinci aşamada merkez tarafından yürütülecek bir işlem de, yazarın bildirdiği bilgilerle tezin ilk kontrolünün yapılmasıdır. Tezin, tesliminden sonra görevli personel tarafından bilgisayarlara indirilmesi (download) veya kopyalanması ve kontrol edilmesi gereklidir. "Elektronik Tez Teslim Formu"nda belirtilen bilgiler ve Jüri Onay Formu ile tezin doğruluğu karşılaştırılmalıdır. Bu noktada bir yanlışlık tespit edilmesi durumunda, daha sonra ortaya çıkabilecek bazı sorunların önüne geçilebilmek için, yazarla iletişim kurulmalı ve yanlışlık düzeltilmelidir. Elektronik Tez Teslim Formunda belirtilen alanlarla ilk kontrolü yapılan tezin, kabul edildiğine dair PDF formatındaki belgenin e-posta ile iletilebilmesi veya elden teslim edilmesi işlemleri çok hızlı bir şekilde yapılmalıdır.

Íkinci Aşama: Elektronik Tez Hizmeti için Yapılan İşlemler

İkinci aşama, e-tezlerin yukarıda belirtilen süreçlerin ardından indekslenmesi, metadata alanların doldurulması, depolama ve arşivleme için format dönüşümü ve erişim yönetimi işlemlerinin yapılmasıdır.

İlk kontrolü yapılan e-tez daha sonra indekslemek üzere ilgili birime iletilir. Burada tezin başlık, içindekiler, öz ve diğer metin bölümleri, herhangi bir kelimeden serbest tarama yapılabilmesi için otomatik indeksleme yöntemleri ile indekslenebilir. $\mathrm{Bu}$ amaçla için otomatik indeksleme yapabilecek programlar temin edilmeli ve bunu kullanacak yetişmiş personel istihdam edilmelidir. Ayrıca tezin yazarı, başlığı, üniversitesi ve bölümü, danışmanı, jüri üyeleri ve tarihi gibi erişim noktalarının belirlenmesi ve konu başlıklarının verilmesi gerekmektedir. Teze ait metadata alanlarının hazırlanması ve konu başlıklarının tesbiti yetişmiş kütüphaneciler tarafından yapılmalıdır.

İndeksleme işlemi yapılan bir e-tez, öncelikle depolama ve arşivleme için belirlenen formatlara dönüştürülmelidir. Yurt dışında uygulanan e-tez projelerinde teknolojik belirsizlikler nedeniyle tezlerin birden çok ve farklı formatlarda elektronik kopyalarının hazırlandığı ve bu kopyaların farklı sunucularda tutulduğu bilinmektedir.

Elektronik tezlerin erişim ve arşivleme kopyası tezin basılı orijinal kopyası ile aynı olan PDF ve Postscript formatlarında olmalıdır. Bunun dışında merkeze gelen kullanıcılara hızı basılı kopya verebilmek için doc veya TeX, LateX formatları ile 
internet tarayıcılarının bilgileri daha hızlı yükleyebilmelerine olanak sağlayan HTML/XML formatı da kullanılmalıdır. Ayrıca herhangi bir formatta çıkabilecek bir soruna karşı herbirinin ayrı ayrı sıkışıııımış elektronik arşiv dosyaları da olmalıdır. Çeşitli formatlara dönüştürülen e-tezler, güvenlik açısından farklı sunucularda saklanmalıdır. Ancak bu format biçimleri, özellikle bilgi teknolojilerindeki hızlı değişime ayak uydurabilecek nitelikte olmalıdır. Yani, gelişen teknolojiye bağlı olarak gerek görüntü ve basılı kopya, gerekse elektronik arşivleme için kullanılan formatlar günün ihtiyaçlarını karşılamaya yönelik olarak güncel tutulmalıdır.

Erişim yönetiminin oluşturulması, e-tez hizmetlerinde yapılması gereken diğer bir işlemdir. Tez yazarlarının "telif hakkı anlaşması" ile verecekleri izinlere bağlı olarak oluşturulacak erişim yönetimiyle kullanıcıların metnin tamamına veya bir kısmına erişmelerinin sağlanması, merkezin önemli görevlerinden birisidir. Kurulacak erişim yönetimi ile elektronik ortamdaki her tez için ayrı ayrı erişim tanımlarının yapılması gerekir. Örneğin, aynı üniversiteye ait farklı tezler için farklı erişim izinleri ortaya çıkabileceği gibi, içeriğine bağlı olarak patent almak için beklenilen bazı tezler belirli bir süre tam metin erişime kapalı tutulabilir. Yurt dışında incelenen bazı örneklerde, tezlerin elektronik tam metinleri, tezin verilmesiyle o üniversite mensuplarının kullanımına hemen sunulmaktadır (North Caroline State University, 2002). Ancak tezin içeriği itibarıyla kabul edildiği üniversite dahil hiçbir araştırmacının kullanımına izin verilmeyen bazı durumların da olabileceği düşünülmelidir.

Dünyada halen yaygın olan kullanıcı adı-şifre uygulamasının yönetimi ve korunmayı tam olarak sağlayamaması, çok güvenli olmaması ve birçok bilgi sistemine girişte kullanıcı adı ve şifrelerin hatırlanmasının zorluğu gibi nedenlerden dolayı kullanışı olmayabilir. Diğer bir erişim yöntemi, bağlanılan bilgisayara ait IP numarası ile kontroldür. IP kontrolü ile erişim, kullanıcı adı-şifreye göre daha kolay ve sık kullanılan bir yöntem olmasına karşın, kullanıcı tek bir mekâna bağımlı kılınmaktadır. Yani kaynağa sadece tanımlanan ağ ile erişimin zorunlu olması kullanım kısıtlaması getirmektedir. Ancak araştırmacıların kurum dışından da araştırmaya ve bilgiye erişmeye gereksinimleri nedeniyle tezlere erişimin mekândan bağımsız olması da istenmektedir.

"Proxy" (vekil) modeli olarak adlandırılan yöntemde ise, diğer modellerde uygulanan işlemlerin vekil makine tarafından yürütülmesi ile kullanım kolaylığı sağlanmaktadır. Kullanıcı adı-şifre ve/veya IP numarası kontrolü ile sisteme bağlantı 
sağlanmasında kontrol ve tanımlama işlemi bu makine tarafından yapılmaktadır. Böylece ana sunucunun yükü hafiflemekte ve bağlantı hızı daha etkin bir şekilde kullanılabilmektedir. Fakat vekil modelinin kurulumunun ve işletilmesinin zaman ve emek isteyen bir çalışma olması, şifrelerin genel kullanıma açık terminallerden de girilebilmesi güvenliği olumsuz yönde etkileyebilmektedir. Ancak diğer yöntemlere göre daha güvenli ve kolay olması nedeniyle tercih edilebilir.

Bunların dışında erişim yönetiminde, elektronik kimlik olarak adlandıılan, kişinin elektronik ortamda kim olduğunu saptayan, tüm kişisel bilgilerin tanımlanmasını yapan sistemler de kullanılmaktadır. Bu sistemde teze erişmek isteyen her kullanıcının kim olduğu tespit edilebilir. Böylece teze ulaşmak isteyen kişinin öğrenci veya öğretim üyesi olup olmadığı, teze erişim izninin bulunup bulunmadığı veya ne kadarını görebileceği gibi detaylı bilgiler ile güvenlik sağlanmış olur. Ancak sistemin kurulmasının ve işletilmesinin zorluğu, maliyetin yüksekliği ve henüz dünyada çok fazla bilgi sisteminde uygulanmaması elektronik kimlik sisteminin olumsuz yönleridir.

Tezler için erişim yönetimi oluşturulduktan sonra tezlerin tam metinlerinin depolanması işlemi gelmektedir. Yazııı ve donanım teknolojilerindeki değişime, etezlerin güvenliğinin sağlanmasına ve sürekli erişilebilir olmasına bağlı olarak önceden belirlenen ve sürekli güncel tutulan formatlara dönüştürülen e-tez, erişim ve arşivleme amacıyla farkı sunucularda depolanmalıdır. Ayrıca sistemin herhangi bir soruna karşı belirli zaman aralıklarında yedeklenmesi de gerekmektedir. Bu noktada, günlük yedeklemenin CD-ROM'lar, haftalık yedeklemelerin ise manyetik bantlar üzerinde yapılması mümkündür.

\section{Üçüncü Aşama: Kullanıcı Erişimi}

Elektronik tez hizmetlerinin üçüncü aşaması, e-tezin kullanıcılar için erişime açılmasıdır. Bu aşamada, tarama ve erişiminde kullanılacak arayüz programının özellikleri, tez erişim formatları ve fiyatlandırma kriterleri önemli noktalardır.

Telif hakkı anlaşması ile belirlenen erişim izinlerine bağlı olarak tezlere erişim hakkı olan kullanıcılar tanımlanmalıır. Kullanıcı arayüzü ile taramasını yapan bir kullanıcının, erişmek istediği tezin durumuna bağlı olarak, kim olduğu, nereden bağlandığı, erişim izninin olup olmadığı ve tezin hangi bölümlerine erişebileceğinin kontrol edilmesi gerekir. Bu konuda geliştirilen başlıca yöntemlere yukarıda kısaca değinilmiştir. 
Ayrıca e-tezlere erişimde üzerinde durulması gereken bir nokta da, kullanıcının erişim izni bulunan tezlerin tarama sonucunda görüntülenmesi veya kaydedilmesine olanak sağlayan otomatik bir bağlantı sisteminin kurulmasıdır. Bu şekilde tasarlanan bir kullanıcı arayüzü ile sunucuya bağlanan kişinin, erişim haklarının sorgulanması ve tanımlanması önceden yapılarak erişebileceği tezlere daha kolay ulaşması sağlanabilir. Örneğin, önceden tanımlanan bir kullanıcı sunucuya bağlanarak tarama yaptığında elde ettiği tez künyelerine ait tam metinler, eğer erişim izni var ise, otomatik olarak aktif hale geçen bir bağlantı ile kullanıma sunulabilir.

Erişim yönetimi ile erişim sınırları belirlenen ve çeşitli formatlarda depolanan tezlerin taramaya ve genel erişime açılması kullanıcı arayüzü ile mümkündür. Kullanıcıların tezi, yazar adı, başlık, üniversite, danışman, anahtar sözcük gibi tüm erişim noktalarından veya metin içinde geçen herhangi bir kelimeden aramasına imkân verecek bir tarama programının olması gerekir. Ayrıca kullanıcıların bilgi arama davranışlarına bağıı olarak tasarlanacak program hem basit (anahtar sözcükle arama), hem de ileri (Boolen işleçleri, yakınlık işleçleri, vb.) arama tekniklerini desteklemelidir.

Tarama sonucunda elde edilen sonuçların görüntülenmesinde ise, genel olarak elektronik bilgi sistemlerinin birçoğunda yazar adı, başlık, tarih, öz gibi alanları kapsayan temel görüntü formatı kullanılabilir. Detay görülmek istendiğinde tarama alanlarındaki tüm metadata alanlarını, içindekiler ve öz kısmını kapsayan bir görüntü formatı tercih edilebilir. Bu görüntü formatlarının her ikisinde de e-tezin erişim izinlerine bağlı olarak, HTML/XML/SGML veya PDF formatlarında açılması sağlanmalıdır.

Erişimine izin verilen e-tez için, gerek internet üzerinden indirilmesi, gerekse merkeze gelerek basılı veya elektronik kopyasının verilmesi sırasında belli oranda bir ücret istenebilir. Fiyatlandırma politikası oluşturulurken tez yazarlarına, tez danışmanlarına veya merkezin bütçesine katkıyla ilgili noktalar göz önüne alınmalıdır. Tez yazarlarına ve danışmanlarına tezin kullanımına bağlı olarak bir ödeme düşünülüyorsa, fiyatlandırma politikasının da buna göre oluşturulması ve bu durumun tezin teslim edilmesi aşamasında Elektronik Tez Teslim Formunda belirtilmesi gerekmektedir. Bu şekilde teze emeği geçenlere ödeme yapılması, hem araştırmacılara maddi ve manevi destek sağlamak hem de diğer araştırmacılara motivasyon kazandırmak açısından önemlidir. 
Tez hizmetlerinin fiyatlandırımasında, merkezin alt yapı ve eleman gereksinimleri de göz önüne alınmalıdır. Böylece araştırmacılara daha iyi hizmet verebilmek için bütçenin bir kısmı da karşılanmış olur. Ancak merkezin kâr amacı gütmediği göz önüne alınarak fiyatlandırmanın maddi kazanç elde etmekten çok, daha iyi hizmet vermek ve maliyetleri karşılamak için olduğu düşünülmelidir.

\section{Sonuç ve Öneriler}

Sürekli olarak gelişen bilgi teknolojileri sayesinde, yurt içi ve yurt dışı bilgi alışverişi ve iletişim de artmaktadır. Buna paralel olarak bilgi kaynaklarında da önemli artışlar gözlenmektedir. Bu nedenle tezlerin hizmete sunulmasında diğer bilgi kaynaklarında olduğu gibi geleneksel yöntemlerin dışına çıkılması ve değişen dünyaya ayak uydurulması gerekmektedir. Bu durum ülkemiz araştırmacıları açısından da büyük önem arz etmektedir.

Bu makalede, ülkemizde üretilen yüksek lisans ve doktora tez çalışmalarının, internet üzerinden tam metin olarak hizmete açılması amacından hareketle, hizmet verecek merkez/merkezler için gereken bileşenlerin neler olduğu anlatılmaya çalışılmıştır. Bu bağlamda üzerinde durulan nokta, elektronik ortamda üretilen tezlerin, yine elektronik formatlarda teslim edilerek hizmete sunulabileceğidir. Bu işlemlerin yapılabilmesi için alt yapı, telif hakları, erişim yönetimi, indeksleme, kullanıcı arayüzü, depolama ve arşivleme, maliyet ve fiyatlandırma ile mevzuat ve yönetmelikler noktalarında ne gibi ihtiyaçların olduğu tespit edilmeye çalışılmıştır.

Türk üniversitelerinde yapılan tezlerin tam metinlerine erişebilmek için uygulanabilecek bazı öneriler şu şekilde özetlenebilir:

- Öğrencilerin e-tezler konusunda geliştirilmeleri amacıyla, bölümler tarafından tez teknik danışmanlığı ve/veya bilgisayar okuryazarlığı dersleri verilmelidir.

- Öğrencilerin e-tez hazırlama sırasında kullanacakları, yazılım ve donanım ürünleri bölümler bünyesinde üniversiteler tarafından sağlanmalıdır.

- Tez yazım ve basım yönetmelikleri ile diğer ilgili mevzuat YÖK aracılığı ile enstitüler tarafından yeniden düzenlenmeli ve standart hale getirilmelidir.

- E-tezlerin indekslenmesinde NDLTD'nin belirlemiş olduğu metadata standardı (ETD-ms) temel alınmalıdır. 
- Üniversite kütüphanelerinin bütçe, teknik personel ve alt yapı sorunları çözümlenerek, Dağııı Sayısal Türkiye Elektronik Tez Merkezi kurulabilmesi için çalışılmalıdır.

- Kütüphaneler ve enstitülerin yukarıda belirtilen intiyaçlarının sağlanmasında ve iletişimin kurulmasında üniversite yönetimleri doğrudan etkili olmalıdır.

- YÖK Dokümantasyon Merkezinin, e-tez çalışmalarına yönelik olarak yeniden düzenlenebilmesi için özellikle bütçe, teknik eleman ve alt yapı konusunda güçlendirilmeli, uzman elemanları kendi kadrosunda istihdam edebilmesi sağlanmalıdır.

- YÖK Dokümantasyon Merkezinin enstitüler ile ilişkileri yeniden düzenlenmeli, bu konuda YÖK tarafından enstitülerin sorumlulukları belirtilmelidir.

- Elektronik tezler konusunda tek bir merkezi yapı düşünülüyorsa, özerk bir yönetime sahip olmalı, özellikle bütçe ve teknik alt yapı konusunda desteklenmelidir.

Bu makalede, Türkiye'de e-tezler konusunda hizmet verecek merkez veya merkezlerin kurulması için yapılması gerekenler kısaca özetlenmektedir. Ancak etezlerin tek bir merkez tarafından hizmete sunulması durumunda, sistemin intiyaçlarının tespit edilmesine ve ortaya çıkabilecek sorunların neler olduğunun saptanmasına yönelik çalışmalar öncelikle yapılmalıdır. Gelişmiş ve gelişmekte olan bir veya birkaç üniversitede bir pilot çalışma başlatılması ve araştırmada değinilen ögeler konusunda daha ayrıntıı olurluk çalışmalarının hazırlanması yerinde olacaktır.

\section{Kaynakça}

Arms, W.Y. (1998). Implementing policies for access management. D-lib Magazine, [Çevrim içi], (February). Elektronik adres:

http://www.dlib.org/dlib/february98/arms/ 02arms.html [20 Aralık 2002].

Bahşişoğlu, H.K. (2000) Türkiye'deki bilgi merkezlerinde gri yayınların sağlanması

üzerine bir inceleme. Yayınlanmamış doktora tezi. Hacettepe Üniversitesi: Ankara.

Boz, M. (2001). Internet üzerinden tezlere tam metin erişim: Türk üniversiteleri için 
kavramsal model önerisi. Yayınlanmamış yüksek lisans tezi. Hacettepe Üniversitesi: Ankara.

Case, M.M. (1998). Electronic theses and dissertations: Inevitable future. ARL Newsletter [Çevrim içi], (201). Elektronik adres: http://www.arl.org/newsltr/ 201/osc-etd.html [20 Aralık 2002].

Dublin Core. (2002). Metadata Initiative Dublin Core Element Set. [Çevrim içi], Elektronik adres: http://dublincore.org/documents/1999/07/02/dces/ [20 Aralık 2002].

Garrett, J.R. (1995). Task force on archiving of digital information. D-Lib Magazine [Çevrim içi], (September). Elektronik adres: http://www.dlib.org/dlib/ september95/09garrett.html [20 Aralık 2002].

Gudivada, V.N., Raghavan, V.V., Grosky, W.I. ve Kasonogottu, R. (1997). Information retrieval on the World Wide Web. IEEE Internet Computing, 1(5): 58-68.

Lynch, C. (1996). Access management for networked information resources. Cause/Effect [Çevrim içi], 21(4). Elektronik adres: http://www.educause.edu/ir/ library/html/cem9842.html [20 Aralık 2002].

McMillan, G., Fox, E.A. ve Eaton, J.L. (1999). The evolving genre of electronic theses and dissertations. 1999 Hawaii International Conference on System Sciences. [Çevrim içi], Elektronik adres: http://scholar.lib.vt.edu/theses/presentations/ Hawaii/ETDgenreALL.pdf [20 Aralık 2002].

NDLTD - Networked Digital Library of Theses and Dissertations. (2001). ETD-Ms: An Interoperability metadata standard for electronic theses and dissertations. [Çevrim içi], Elektronik adres: http://www.ndltd.org/standards/metadata/ current.html [20 Aralık 2002].

North Carolina State University. (2002). Electronic Thesis and Dissertation : Steps in the ETD Submission Process. [Çevrim içi], Elektronik adres: http://www2.acs.ncsu.edu/ grad/ETD/steps.htm [20 Aralık 2002].

Prytherch, R.J. (1995). Harrod's librarians' glossary: 9000 terms used in information management, library science publishing, the book trade and archive management. Brookfield, VT: Gower. 
Rusbridge, C. (1995). Copyright Issues for the Electronic Library. [Çevrim içi], Elektronik adres: http://www.jisc.ac.uk/pub/copyright/chrisrus.htm [20 Aralık 2002].

Thomas, S. (1998). Cornell University Library Publication of Electronic Dissertations. [Çevrim içi], Elektronik adres:

http://www.library.cornell.edu/staffweb/ETDSTUDY.HTML [20 Aralık 2002].

Tonta, A.Y. (1999). Elektronik Bilgilerin Korunması ve Arşivlenmesi. [Çevrim içi], Elektronik adres:

http://yunus.hacettepe.edu.tr/ tonta/courses/fall99/kut655/arsivleme.htm [20 Aralık 2002].

Virginia Tech University Libraries. (1998). Archiving Electronic Theses and Dissertations: The Virginia Tech Experience. [Çevrim içi], Elektronik adres: http://scholar.lib.vt.edu/theses/archive.html [20 Aralık 2002].

Waterloo University Electronic Thesis Project Team. (1997). Terms of Reference and Team Members. [Çevrim içi], Elektronik adres: http://www.lib.uwaterloo.ca/ uwetpt/terms.html [20 Aralık 2002].

\section{Yardımcı Kaynakça}

Berkeley Digital Library SunSite. (1996). Digital Library SunSite Collection and Preservation Policy. [Çevrim içi], Elektronik adres: http://sunsite.berkeley.edu/ admin/ collection.html [20 Aralık 2002].

Davis J.R. (1995). Creating a networked computer science technical report library. DLib Magazine [Çevrim içi], (September). Elektronik adres: http://www.dlib.org/dlib/ september95/09davis.html. [20 Aralık 2002].

Davis J.R., Fielding, D., Lagoze, C. ve Marisa, R. (2000). Dienst Protocol Version 4.1. [Çevrim içi], Elektronik adres:

http://www.cs.cornell.edu/cdlrg/dienst/protocols/_DienstProtocol.htm [20 Aralık 2002].

Glenn, A. ve Millman, D. (1998). Access management of web-based services. D-lib Magazine [Çevrim içi], September. Elektronik adres: http://www.dlib.org/dlib/ 
september98/millman/09millman.html [20 Aralık 2002].

Graham, P.S. (1994). Intellectual preservation: Electronic preservation of the third kind. The LIBER Quarterly, 4:163-174.

Hedstrom, M. (2002). Digital Preservation: A Time Bomb for Digital Libraries. [Çevrim içi], Elektronik adres: http://www.uky.edu/ kiernan/DL/hendstrom.html [20 Aralık 2002].

Marcum, D.B. (1999) New agenda for the Council on Library and Information Resources. D-lib Magazine [Çevrim içi], 5(6). Elektronik adres:

http://www.dlib.org/dlib/june99/06clips.html\#MARCUM [20 Aralık 2002].

Petersen, R.J. (1999). Copyright ownership issues and higher education policies. Dlib Magazine [Çevrim içi], 5 (6). Elektronik adres: http://www.dlib.org/dlib/june99/ o6clips.html [20 Aralık 2002].

Waters, D.J. (1995). The implications of the draft report of the task force on digital archiving. Building Partnerships that Shape the Future Association of Research Libraries Proceedings of the 127th Annual Meeting Washington, D.C. October 18-20, 1995 içinde [Çevrim içi], Elektronik adres: http://arl.cni.org/arl/ proceedings/127/waters.html [20 Aralık 2002].

Witten I.H., Mcnab, R.J., Jones, S., Apperley, M., Bainbridge, D. ve Cunningham, S. (1999). Managing complexity in a distributed digital library. Computer. 32(2): 74.

YÖK. (1987). Gazi Üniversitesi Rektörlüğüne 1.7.1987 tarih YAY-Dok/10.01.001 / 2235 sayılı yazı.

YÖK. (1995).Üniversite Rektörlüklerine 7.6.1995 ve B.30.0.YDB.0.00.00.04/ 323 sayılı yazı.

YÖK. (1997). Üniversite Rektörlüklerine 9.7.1997 ve B.30.0.YDB.0.00.00.02/ 267 sayılı yazısı. 


\section{Ek: Elektronik Tez Teslim Formu*}

\section{Elektronik Tez Teslim Formu}

Tezinizi teslim etmeden önce, Elektronik Tez Teslim Prosedürlerini okuyunuz.

Başlamadan önce Tarayıcı pencerenizi büyülttün.

Doküman Tipi: (Teslim edeceğiniz dokümanın türünü seçiniz.)

Yüksek Lisans Tezi

Adınız ve Soyadınız (Adınızı ve Soyadınızı tez başlığında göründüğü şekliyle yazınız.)

Soyadınız:

$\mathrm{BOZ}$

Adınız ve varsa ikinci adınız:

Mehmet

E-posta adresiniz. (E-posta adresinizi giriniz.)

mehmet@ulakbim.gov.tr

Başık. (Tez başıı̆ınızı, Tezinizde göründüğü şekliyle giriniz.)

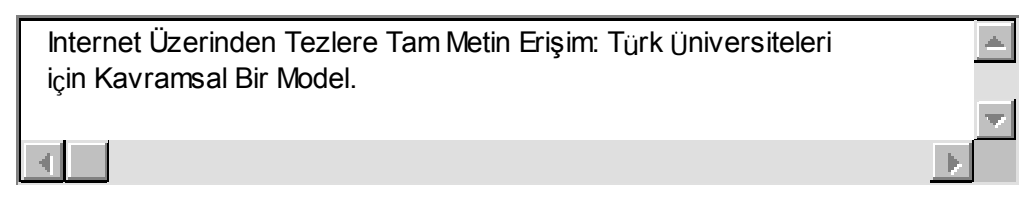

Derece:

Yüksek Lisans

Üniversite Adı:

Hacettepe Üniversitesi

\section{Bölüm/Program:}

Kütüphanecilik

Danışman/Jüri:(Danışman ve Jüri üyelerinin adı, soyadı, görevleri ve varsa e-posta adresini belirtiniz.)

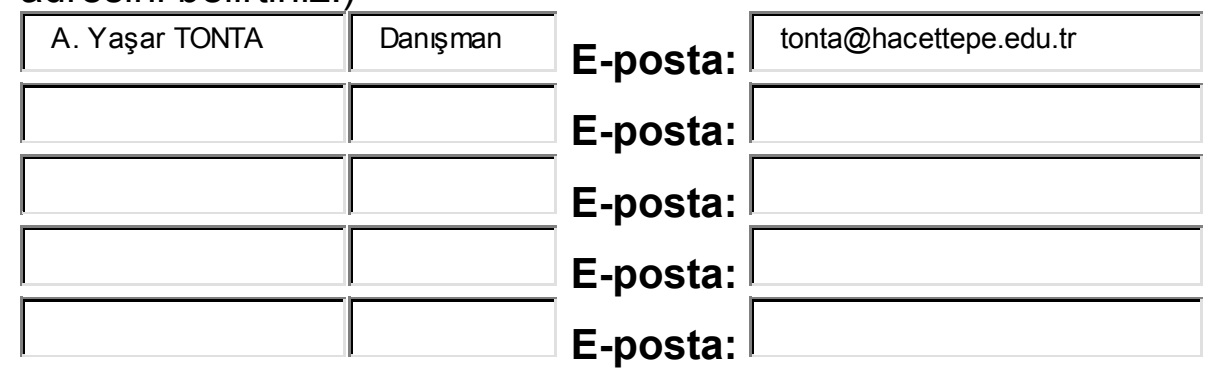

Anahtar kelimeler ve cümleler:

Anahtar Kelime yardımı

* (Boz, 2001, s.116). 
Anahtar kelimelerinizi virgül (,) ile ayırarak giriniz (Örn: Elektronik Tez, E-tez, Türkiye).

Elektronik Tez, E-tez, Türkiye, Tez Hizmetleri, ETD.

Savunma Tarihiniz:

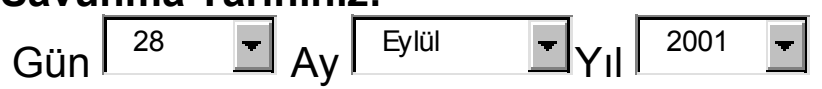

\section{Öz (Abstract):}

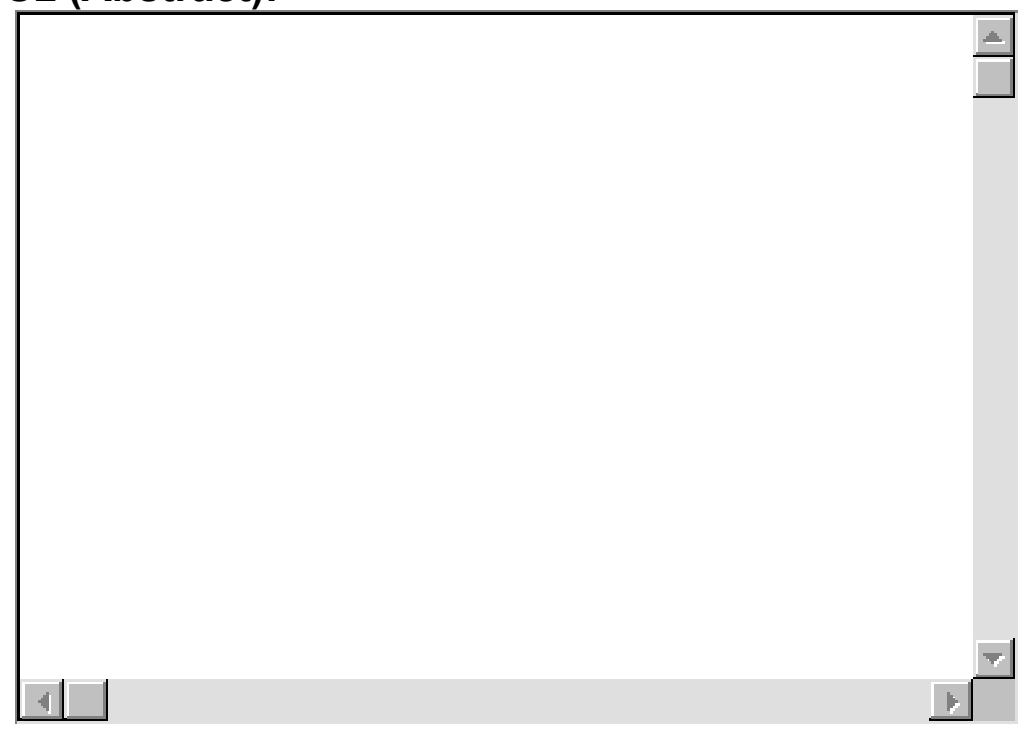

\section{Telif Hakkı Anlaşması:}

Bu anlaşma ile Tez çalışmamın, Merkez tarafından her türlü elektronik formatta arşivlenmesine ve kullanılmasına, tüm mülkiyet ve patent hakları ile tezimin tümü veya bir bölümü ile gelecekte yapacağım çalışmaların (makale, kitap vb.) kullanım haklarını elimde tutmak koşuluyla, izin veriyorum.
- Kabul ediyorum
Kabul etmiyorum

\section{Uygunluk:}

Çalışmanızı ne zaman genel kullanıma açmak istersiniz.

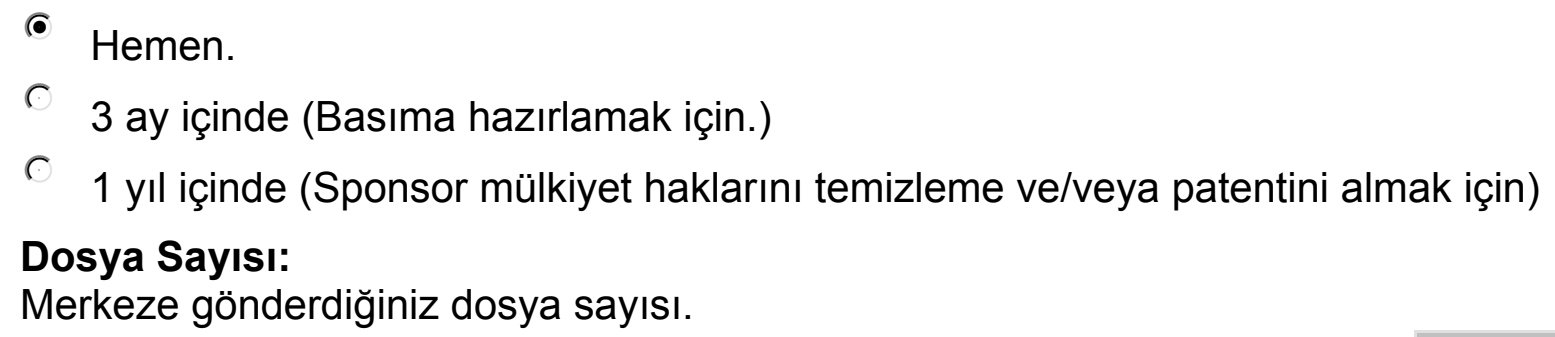

Önizleme: Devam etmek için "önizleme" tuşuna basın. 